\title{
ProMark Proteomic Prognostic Test
}

National Cancer Institute

\section{Source}

National Cancer Institute. ProMark Proteomic Prognostic Test. NCI Thesaurus. Code C162576.

A proprietary tissue-based test that uses multiplex immunofluorescent staining with monoclonal antibodies to provide a personalized prediction for prostate cancer aggressiveness. It detects an 8-protein signature (DERL1, CUL2, SMAD4, PDSS2, HSPA9, FUS, pS6 (phosphorylated S6), YBOX1). 